\title{
INFLUÊNCIA DO ÁCIDO INDOLBUTÍRICO E DA MINIESTAQUIA SERIADA NO ENRAIZAMENTO E VIGOR DE MINIESTACAS DE CLONES DE Eucalyptus grandis 1
}

\author{
Ivar Wendling ${ }^{2}$ e Aloisio Xavier ${ }^{3}$
}

\begin{abstract}
RESUMO - O presente estudo objetivou avaliar a eficiência da miniestaquia seriada e o efeito da aplicação do regulador de crescimento ácido indolbutírico (AIB), nas concentrações de $0,500,1.500$ e $3.000 \mathrm{mg} \mathrm{L}^{-1}$, em relação à sobrevivência, ao enraizamento e vigor da parte aérea e do sistema radicular de miniestacas em quatro clones de Eucalyptus grandis. Com base nos resultados, a aplicação do AIB não resultou em aumento do enraizamento e sobrevivência das miniestacas e no vigor geral das mudas, sendo em algumas características e clones observados certos níveis de toxidez nas concentrações acima de $500 \mathrm{mg} \mathrm{L}^{-1}$. Em relação à miniestaquia seriada, esta proporcionou maior eficiência na propagação vegetativa dos clones de Eucalyptus grandis com menor grau de juvenilidade.
\end{abstract}

Palavras-chave: Rejuvenescimento, Eucalyptus, propagação vegetativa e silvicultura clonal.

\section{INDOLBUTIRIC ACID AND SERIAL MINICUTTING TECHNIQUE ON ROOTING AND VIGOR OF Eucalyptus grandis CLONE MINICUTTINGS}

\begin{abstract}
The objective of this work was to evaluate the efficiency of the serial minicutting technique and the effects of different dosages $\left(0,500,1500\right.$ and $\left.3000 \mathrm{mg} \mathrm{L}^{-1}\right)$ of the growth regulator indolbutiric acid (IBA), on the survival, rooting and radicular vigor of minicuttings in clones of Eucalyptus grandis. The IBA application caused no increase in rooting, survival and radicular vigor of the seedlings. In some evaluated characteristics and clones, toxic effects were found in concentrations of AIB above $500 \mathrm{mg} \mathrm{L}^{-1}$. The serial minicutting technique provided greater efficiency for the vegetative propagation of less-juvenile Eucalyptus grandis clones.
\end{abstract}

Keywords: Rejuvenation, Eucalyptus, vegetative propagation and clonal forestry.

\section{INTRODUÇÃO}

A propagação vegetativa de Eucalyptus no Brasil, em escala comercial, passou por inúmeras transformações, tendo-se iniciado com a técnica de estaquia e implementada no final da década de 1970 (IKEMORI, 1975). Desde o início da sua implementação, os reguladores de crescimento, principalmente as auxinas, sempre estiveram presentes nos trabalhos de propagação, uma vez que proporcionam maior porcentagem, velocidade, qualidade e uniformidade de enraizamento (HARTMANN et al., 1997), embora a sensibilidade das células vegetais (LOPES e BARBOSA, 1988) e clones (LAINE e DAVID, 1994) sejam variáveis.

As concentrações de regulador de crescimento aplicadas variam em função da espécie (WILSON, 1994), de clone (CHUNG e LEE, 1994), de estado de maturação dos propágulos (WILSON, 1994; KAMLESH et al., 1995) e da forma de aplicação, entre outros fatores. Em

\footnotetext{
${ }^{1}$ Recebido em 16.06.2003 e aceito para publicação em 10.08.2005.

${ }^{2}$ Embrapa Florestas, 83411-000 Colombro-PR. E-mail:<ivar@empf.embrapa.br $>$.

${ }^{3}$ Departamento de Engenharia Florestal da UFV, 36570-000 Viçosa-MG. E-mail:<xavier@ufv.br>.
} 
Eucalyptus spp., e com a técnica de miniestaquia, variam desde a não-aplicação até $2.000 \mathrm{mg} \mathrm{L}^{-1}$ (WENDLING, 1999; TITON, 2001; XAVIER et al., 2001), já na microestaquia Xavier e Comério (1996) recomendaram o enraizamento sem a aplicação de regulador de crescimento.

O rejuvenescimento de clones consiste em reverter plantas ou parte delas de um estado maduro para um estado juvenil. Segundo Franclet et al. (1987), a técnica da micropropagação é eficiente para o rejuvenescimento, enquanto para Huang et al. (1990) a enxertia seriada é o mais consistente método de rejuvenescimento e o mais utilizado. O efeito da confecção de estacas de brotações das estacas enraizadas sobre o rejuvenescimento em Eucalyptus spp., resultando em efeitos positivos sobre o enraizamento, foi citado por Eldridge et al. (1994), embora ainda haja poucos relatos nesse sentido.

Em detrimento dessas colocações e em razão do atual esparso conhecimento disponível em relação aos aspectos de juvenilidade, aliada à grande variabilidade de ações e efeitos dos reguladores de crescimento vegetais em plantas, tornam-se imprescindíveis estudos nessa linha do conhecimento. Assim, o presente estudo objetivou avaliar a eficiência da miniestaquia seriada e o efeito da aplicação de diferentes concentrações de ácido indolbutírico (AIB) na sobrevivência, no enraizamento e no vigor da parte aérea e do sistema radicular de miniestacas de quatro clones de Eucalyptus grandis.

\section{MATERIAL E MÉTODOS}

O experimento foi conduzido na Empresa Celulose Nipo-brasileira S.A. - CENIBRA, Belo Oriente, MG. Foram utilizados quatro clones de Eucalyptus grandis (CC10, CC12, CC14 e CC15), selecionados em uma população de procedência de Rio Claro, SP, e propagados vegetativamente a partir da técnica de estaquia convencional.

A partir de minicepas formadas de mudas produzidas pelo processo de estaquia convencional (jardim 0), foram obtidas as miniestacas, que foram enraizadas em casa de vegetação, com temperatura em torno de $27{ }^{\circ} \mathrm{C}$ e umidade relativa do ar superior a $80 \%$. As miniestacas permaneceram em casa de vegetação por 25 dias, em casa de sombra por mais 10 dias e, posteriormente, em rustificação a pleno sol, em que, após 20 dias, foram podadas para formação das minicepas do subcultivo 1 .

As mudas formadas a partir das miniestacas enraizadas do subcultivo 1 , ao atingirem 10 a $12 \mathrm{~cm}$ de altura, tiveram seu ápice podado a $6-8 \mathrm{~cm}$ da base, formando, assim, as minicepas do subcultivo 2, que, após 20-30 dias, forneceram as brotações (miniestacas). As minicepas do subcultivo 2, de forma similar, forneceram novas miniestacas para formação do jardim miniclonal do subcultivo 3 , e assim sucessivamente até o subcultivo 7. Dessa maneira, foram formados sete jardins miniclonais (jardim 0, 1, 2, 3, 4, 5 e 6), ou seja, sete subcultivos de miniestaquia (subcultivos 1,2 , 3, 4, 5, 6 e 7).

Ojardim miniclonal foi instalado em ambiente coberto por plástico transparente e conduzido em sistema de hidroponia em calhetão com aproximadamente 100 minicepas por metro quadrado, sendo cada clone representado por 130 minicepas por subcultivo. Em períodos regulares de 5 a 10 dias, as minicepas receberam podas seletivas para coleta de miniestacas, as quais foram mantidas durante toda a fase experimental, visando a um manejo adequado das minicepas nos jardins miniclonais. A nutrição mineral adotada foi balanceada, de modo a se obter um bom padrão de vigor das minicepas, conforme Wendling (2002).

Uma vez formados os jardins miniclonais dos sete subcultivos, conforme mencionado anteriormente, coletaram-se simultaneamente, miniestacas dos jardins de subcultivos zero (jardim formado de mudas originárias de estacas), 2, 4 e 6, após a sua formação ter sido completada. Desses jardins foram enraizadas miniestacas e formadas as minicepas para os jardins utilizados na experimentação (jardim miniclonal de subcultivos 1 , 3,5 e 7), os quais forneceram as miniestacas para os testes comparativos. Tal procedimento, além de facilitar a operacionalização dos testes comparativos entre os subcultivos, visou também à padronização da idade das minicepas de todos os subcultivos, para posterior coleta de miniestacas.

Para o enraizamento e formação das mudas, as miniestacas foram enraizadas em tubetes plásticos de $55 \mathrm{~cm}^{3}$, contendo substrato formado pela mistura em partes iguais de vermiculita de granulometria média e casca de arroz carbonizada. As miniestacas permaneceram em torno de 25 dias na casa de vegetação, seguindo posteriormente para a casa de sombra, onde 
permaneceram por mais 10 dias, para aclimatação e rustificação a pleno sol, em que, aos 50 dias de idade, foi realizada a avaliação final.

Buscando avaliar o efeito do regulador de crescimento AIB no enraizamento das miniestacas, foram testadas quatro concentrações $\left(0,500,1.500\right.$ e $\left.3.000 \mathrm{mg} \mathrm{L}^{-1}\right)$, via solução, diluídas em hidróxido de sódio $(\mathrm{NaOH})$, durante 10 segundos, antes de serem estaqueadas no substrato.

Foi avaliado o crescimento em altura, diâmetro de colo e peso da matéria seca das partes aérea e radicular aos 50 dias, bem como a sobrevivência das mudas na saída da casa de vegetação (aos 25 dias), de sombra (aos 35 dias) e a pleno sol (aos 50 dias). O delineamento experimental utilizado foi o inteiramente casualizado, em arranjo fatorial 4 x 4 × 4 (quatro subcultivos, quatro concentrações de AIB e quatro clones), com cinco repetições e 16 miniestacas por repetição. Os dados de sobrevivência na saída da casa de vegetação foram

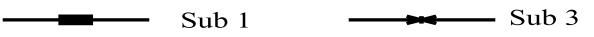

\section{Clone CC10}

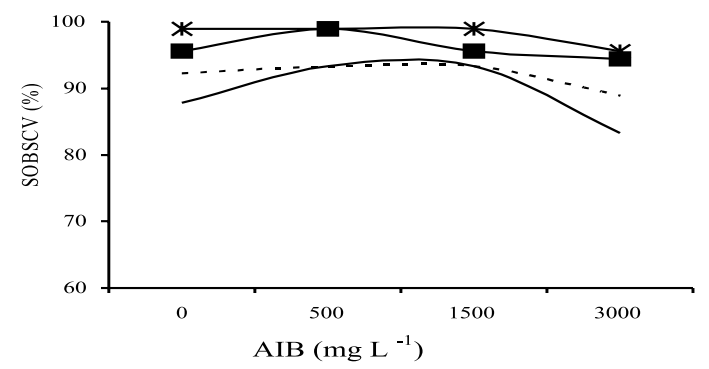

Clone CC14

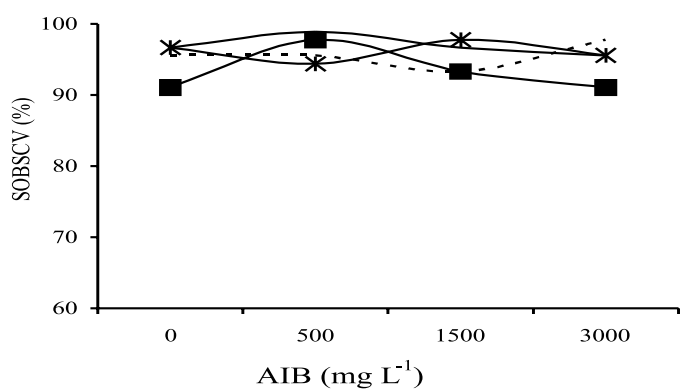

transformados por Asen $\sqrt{\left(\frac{X}{100}\right)}$; os de enraizamento na saída da casa de sombra e sobrevivência aos 50 dias, por Asen $\sqrt{\left(\frac{X}{100}-0,1\right)} ;$ e os de matéria seca da parte aérea e radicular, por $\log 10(\mathrm{X}+20)$. Os dados resultantes foram analisados por meio de análises de variância e regressão.

\section{RESULTADOS E DISCUSSÕES}

\subsection{Enraizamento e sobrevivência das miniestacas}

Na saída da casa de vegetação (Figura 1), observamse valores de sobrevivência próximos a $100 \%$ em todos os clones, não havendo diferenças entre os subcultivos de miniestaquia e entre as concentrações de AIB. Esse comportamento pode ser devido ao fato de a sobrevivência na saída da casa de vegetação ainda não ser uma avaliação que mostre grandes diferenças, pois as condições ambientais ainda são controladas e favoráveis à manutenção da sobrevivência das miniestacas.

\section{- . . - Sub $5 \quad$ Sub 7}

\section{Clone CC15}

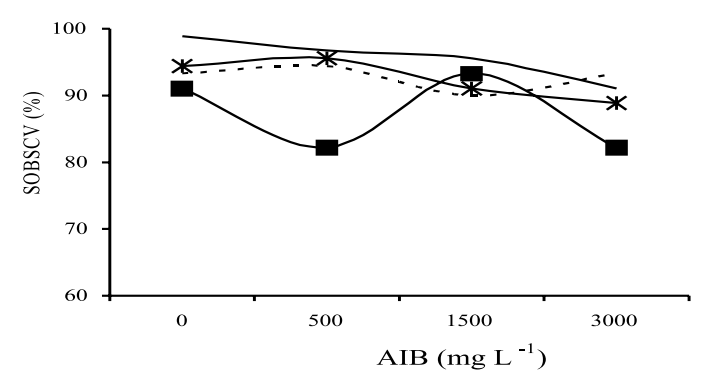

Clone CC12

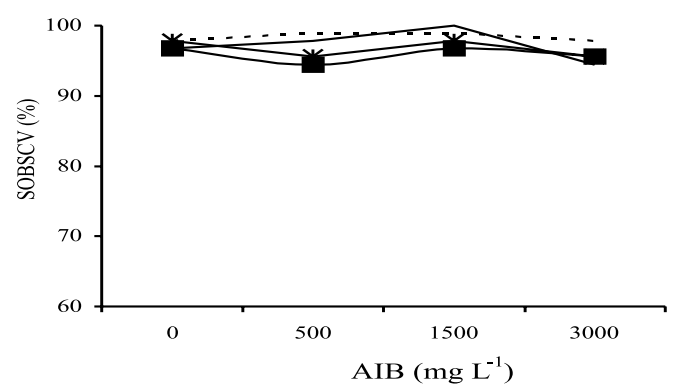

Figura 1 - Médias de sobrevivência das miniestacas na saída da casa de vegetação (SOBSCV), em resposta à aplicação de AIB $\left(0,500,1.500\right.$ e $\left.3.000 \mathrm{mg} \mathrm{L}^{-1}\right)$, nos quatro subcultivos (Sub 1, Sub 3, Sub 5 e Sub 7) de miniestaquia seriada de clones de Eucalyptus grandis.

Figure 1 - Survival (SOBSCV) of minicuttings of Eucalyptus grandis clones in response to the growth regulator AIB application and four serial minicutting subcultures, evaluated at greenhouse exit. 
Já na saída da casa de sombra (Figura 2), observouse pequena redução nos índices de sobrevivência em relação à saída da casa de vegetação, principalmente nos clones CC10 e CC15. Os clones CC14 e CC12 não apresentaram, novamente, diferenças entre os subcultivos de miniestaquia e entre as diferentes concentrações de AIB; já nos clones $\mathrm{CC} 10$ e CC15 notou-se uma pequena superioridade do subcultivo 7 , principalmente em relação aos subcultivos 1 e 3 .

Os clones CC10 e CC15 apresentaram maior redução nos valores de sobrevivência aos 50 dias de idade (Figura 3) em relação aos da saída da casa de sombra. Tal comportamento pode estar relacionado aos efeitos de maiores estresses hídrico e lumínico encontrados na área de aclimatação, indicando que os subcultivos maiores resultaram em maior resistência às condições ambientais adversas para esses clones.

Os subcultivos de miniestaquia seriada foram eficientes na promoção de maiores índices de sobrevivência aos 50 dias de idade das mudas, independentemente das concentrações de AIB aplicadas, somente nos clones CC10 e CC15. No clone CC10, a média geral de sobrevivência foi de $45,1 \%$ nos subcultivos 1 e 3 e 73,7\% nos 5 e 7, resultando em aumento de $28,6 \%$ na taxa de sobrevivência nos subcultivos maiores. No clone CC15, os subcultivos 1 e 3 apresentaram valores de $47,8 \%$ de sobrevivência, e os subcultivos 5 e 7 , $76,3 \%$ resultando em $28,4 \%$ de aumento na sobrevivência.

Quando se compararam os resultados de sobrevivência em termos de clones, observou-se a superioridade do clone CC12 em relação aos demais, seguido pelo CC14. Nesses dois clones, novamente não se observaram efeitos dos subcultivos de miniestaquia seriada sobre o rejuvenescimento, uma vez que são clones com bom grau de juvenilidade, concordando com os resultados de Titon (2001) e Xavier et al. (2001), que trabalharam com os mesmos clones de Eucalyptus.

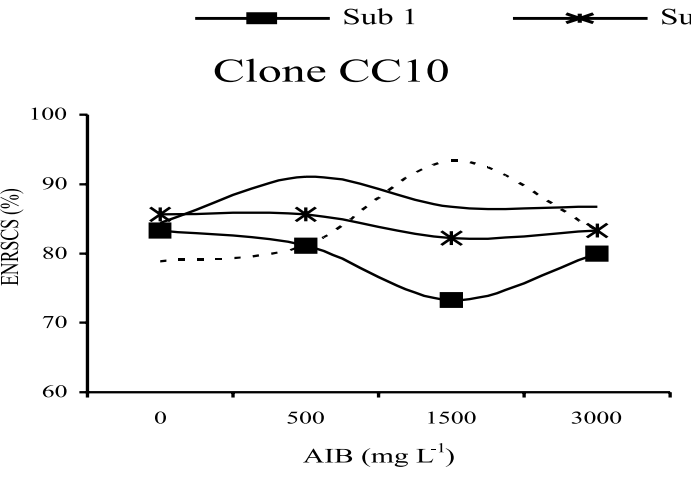

Clone CC14

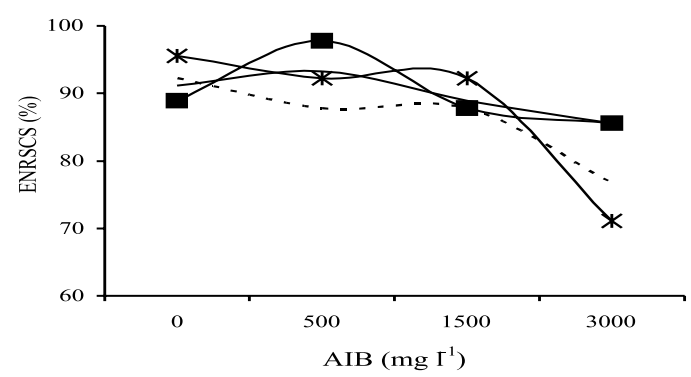

- . - - Sub 5

Clone CC15

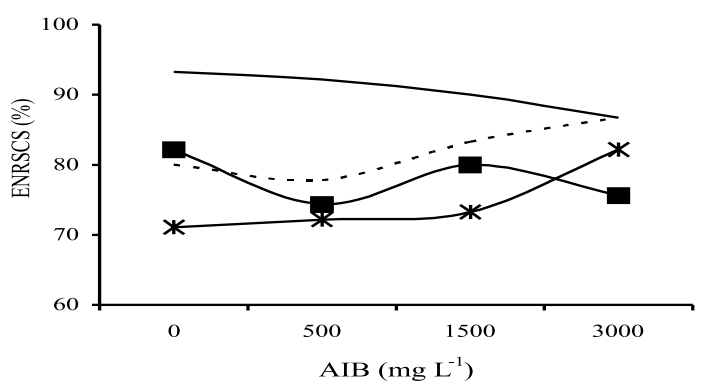

Clone CC12

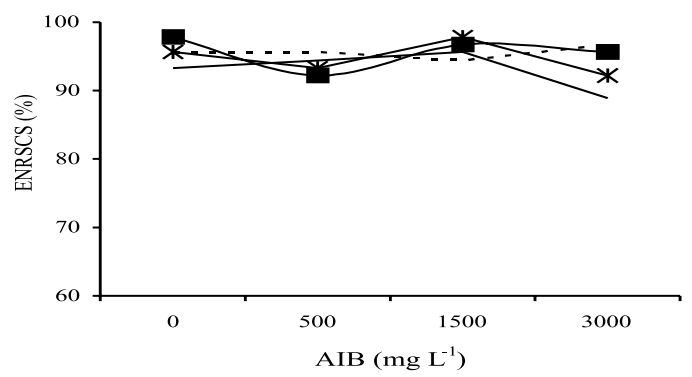

Figura 2 - Médias de enraizamento das miniestacas na saída da casa de sombra (ENRSCS), em resposta à aplicação de AIB $\left(0,500,1.500\right.$ e $\left.3.000 \mathrm{mg} \mathrm{L}^{-1}\right)$, nos quatro subcultivos (Sub 1, Sub 3, Sub 5 e Sub 7) de miniestaquia seriada de clones de Eucalyptus grandis.

Figure 2 -Rooting (ENRSCS) of minicuttings of Eucalyptus grandis clones in response to the growth regulator AIB application and four serial minicutting subcultures, evaluated at the shade house exit .

R. Árvore, Viçosa-MG, v.29, n.6, p.921-930, 2005 

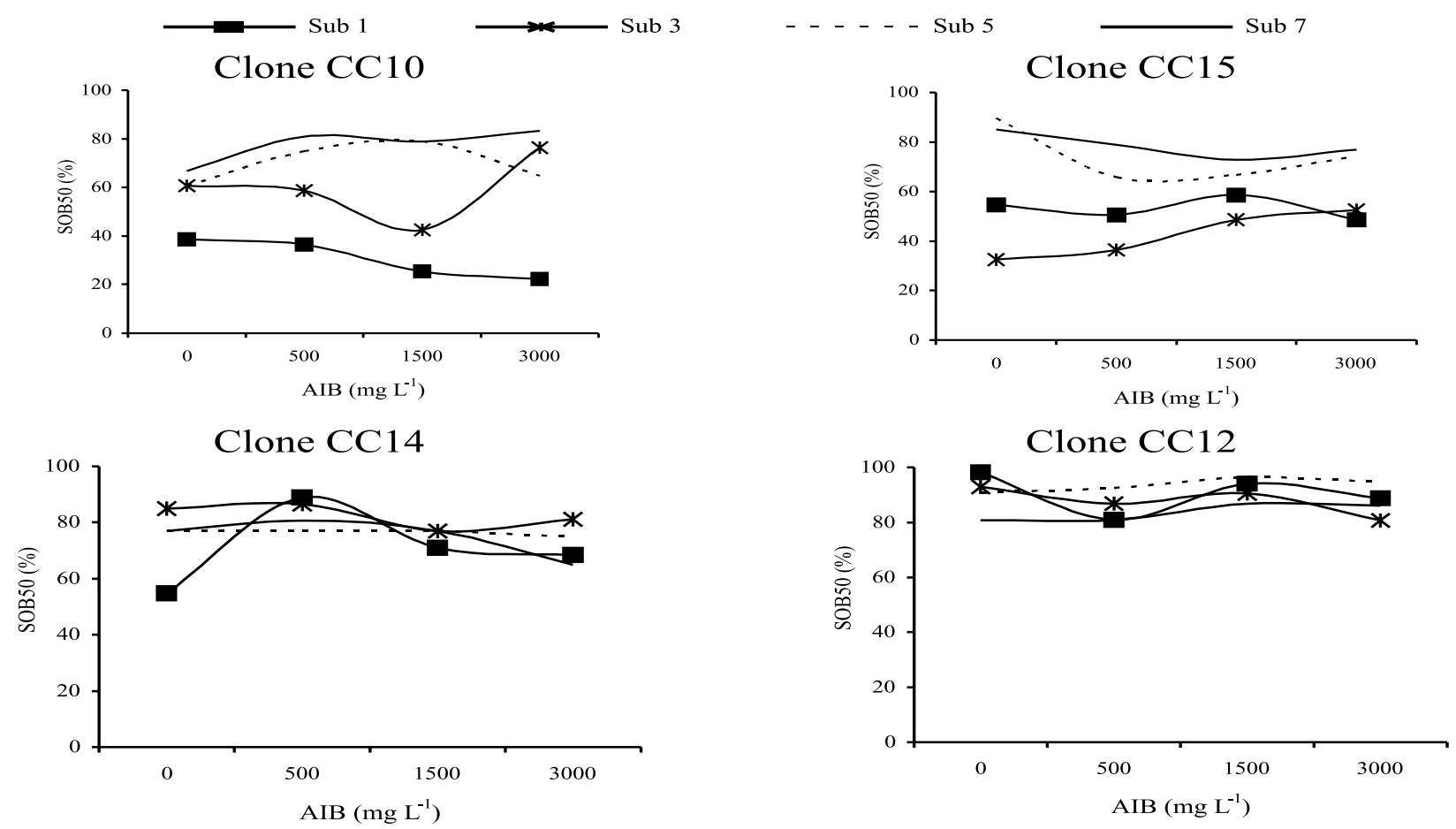

Figura 3 - Médias de sobrevivência das mudas aos 50 dias (SOB50), em resposta à aplicação de AIB (0, 500, 1.500 e 3.000 $\mathrm{mg} \mathrm{L}^{-1}$ ), nos quatro subcultivos (Sub 1, Sub 3, Sub 5 e Sub 7) de miniestaquia seriada de clones de Eucalyptus grandis.

Figure 3 - Survival (SOBSCV) of minicuttings of Eucalyptus grandis clonesat 50 days in response to the growth regulator AIB application and four serial minicutting subcultures.

No que tange à aplicação de AIB, não se observaram efeitos das diferentes concentrações em relação à sobrevivência dos clones CC14 e CC12. Já nos clones CC10 e CC15 observaram-se respostas diferenciadas à aplicação de AIB, não havendo, entretanto, tendência clara de efeito positivo ou negativo. Tais resultados são contrários aos encontrados por Wendling (1999) em miniestaquia de clones de Eucalyptus spp., em que as concentrações entre 1.000 e $2.000 \mathrm{mg} \mathrm{L}^{-1}$ foram mais eficientes no enraizamento.

De acordo com Alvarenga e Carvalho (1983) e Hartmann et al. (1997), quando a auxina é aplicada em estacas ocorre aumento da sua concentração, o que produz efeito estimulador na indução de raízes até um ponto máximo, a partir do qual qualquer acréscimo do nível de auxina se torna inibitório. Assim, no presente estudo, provavelmente a concentração interna de auxina foi suficiente para promover a indução das raízes, embora os índices gerais de enraizamento tenham sido mais baixos nos clones CC10 e CC15, o que significa uma possível consequiência de um menor vigor dos propágulos. Observo-se efeito inibitório do clone CC10 no subcultivo 1 e em concentrações maiores que $500 \mathrm{mg} \mathrm{L}^{-1}$ e no subcultivo 5 em concentrações acima de $1.500 \mathrm{mg} \mathrm{L}^{-1}$, enquanto no clone $\mathrm{CC} 15$, nos subcultivos 5 e 7 , tal fato ocorreu nas concentrações acima de $500 \mathrm{mg} \mathrm{L}^{-1}$.

Materiais mais juvenis não necessitam, entretanto de aplicações de AIB para incrementar o enraizamento (ASSIS et al., 1992; XAVIER e COMÉRIO, 1996). Assim, no presente estudo, em que não foram observados efeitos positivos da aplicação de AIB sobre a sobrevivência e enraizamento das miniestacas, podese supor que os conteúdos hormonais internos foram suficientes para promover um bom enraizamento.

\subsection{Altura e diâmetro de colo das mudas aos 50 dias}

Em termos de altura e diâmetro de colo das mudas aos 50 dias de idade, conforme Figuras 4 e 5, respectivamente, notou-se a superioridade dos clones CC14 e CC12 em relação aos demais.

R. Árvore, Viçosa-MG, v.29, n.6, p.921-930, 2005 


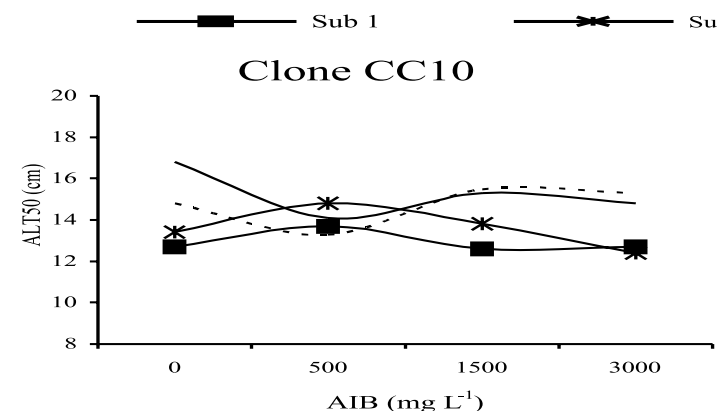

Clone CC14

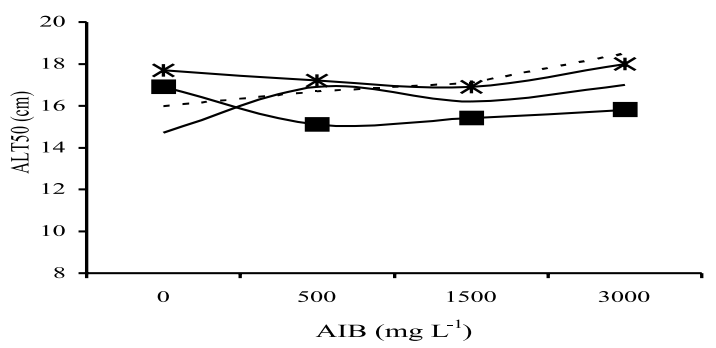

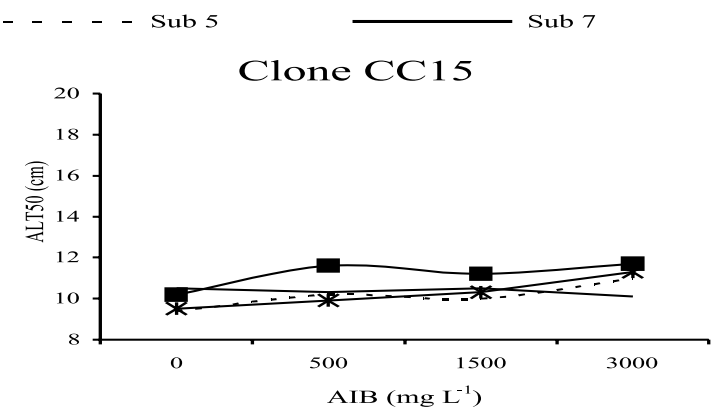

Clone $\mathrm{CC} 12$

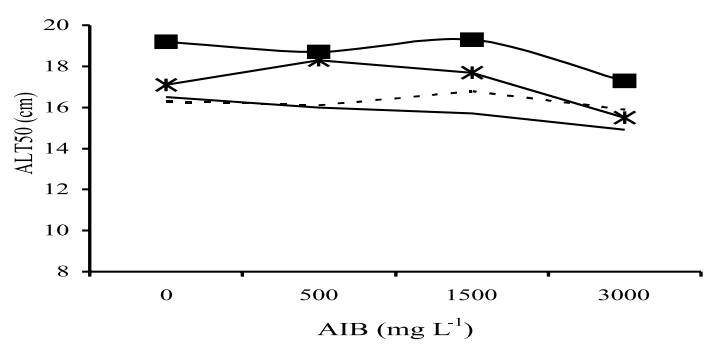

Figura 4 - Médias de altura das mudas aos 50 dias (ALT50), em resposta à aplicação de AIB (0, 500, 1.500 e $\left.3.000 \mathrm{mg} \mathrm{L}^{-1}\right)$, nos quatro subcultivos (Sub 1, Sub 3, Sub 5 e Sub 7) de miniestaquia seriada de quatro clones de Eucalyptus grandis.

Figure 4 - Growth in height of rooted seedlings at 50 days of age (Alt50) of minicuttings of Eucalyptus clones in response to different dosages of the growth regulator AIB and four serial minicutting subcultures.

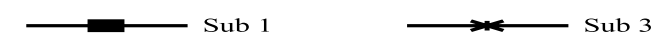

Clone CC10

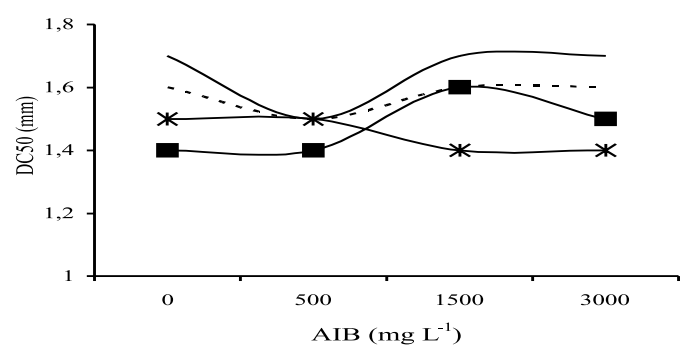

Clone CC14

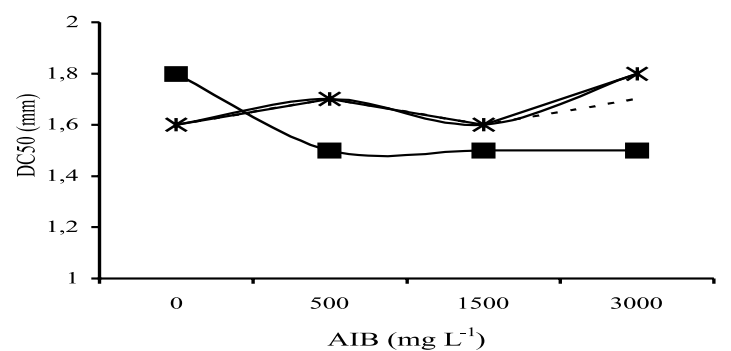

Clone CC15

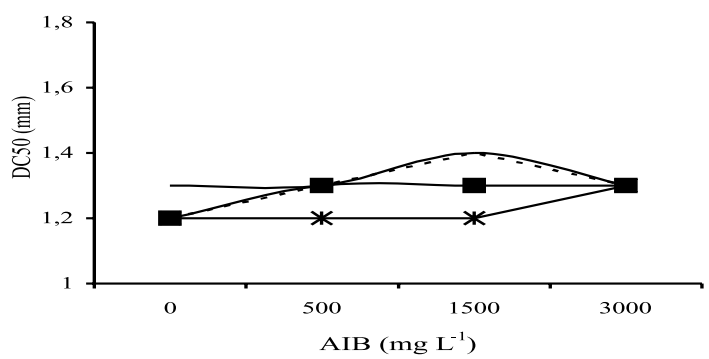

Clone CC12

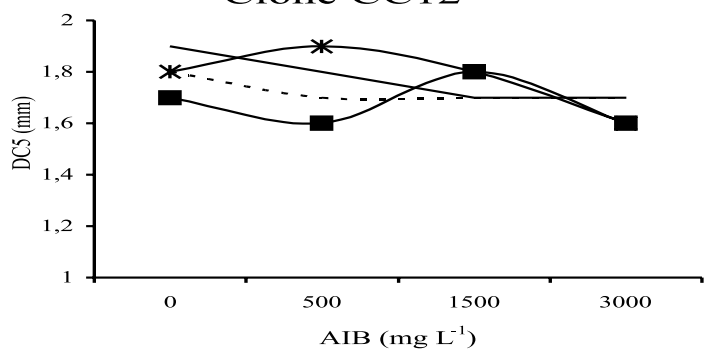

Figura 5 - Médias do diâmetro de colo das mudas aos 50 dias (DC50), em resposta à aplicação de AIB (0, 500, 1.500 e 3.000 $\mathrm{mg} \mathrm{L}^{-1}$ ), nos quatro subcultivos (Sub 1, Sub 3, Sub 5 e Sub 7) de miniestaquia seriada de clones de Eucalyptus grandis.

Figure 5 - Growth in root collar diameter of rooted seedlings at 50 days of age (DC50), of minicuttings of Eucalyptus clones, in response of different dosages of the growth regulator AIB and four serial minicuttings subcultures.

R. Árvore, Viçosa-MG, v.29, n.6, p.921-930, 2005 
Nos subcultivos de miniestaquia seriada, no que se relaciona à altura das mudas aos 50 dias, observouse que o clone de maior aptidão à propagação vegetativa (CC12) apresentou resposta negativa. Porém, o fato de a altura ser uma característica facilmente modificada em razão do manejo adotado na produção das mudas (CARNEIRO, 1995) pode resultar em efeito dominante dessa ação quanto aos resultados promovidos pelo rejuvenescimento, principalmente quando se trabalha com clones com bom grau de juvenilidade, aqui demonstrado pelos altos índices de enraizamento e sobrevivência encontrados no clone CC12, conforme descrito com relação à sobrevivência das mudas aos 50 dias.

Nos demais clones, nos quatro subcultivos de miniestaquia seriada não foram observadas diferenças de crescimento, levando-se à confirmação da teoria de Hackett e Murray (1993) de que o rejuvenescimento ocorre em termos relativos e não absolutos, uma vez que algumas características relacionadas à maturação são mais facilmente rejuvenescidas que outras, o que pode ser visualizado pelos índices de sobrevivência aos 50 dias dos clones CC10 e CC15.

No que se relaciona ao diâmetro de colo das mudas aos 50 dias de idade, não foram observados efeitos dos subcultivos de miniestaquia seriada. Segundo Carneiro (1995), essa também é uma característica facilmente modificada em função do manejo adotado na produção das mudas, podendo, novamente, ter resultado em efeito dominante dessa ação em relação aos resultados promovidos pelo rejuvenescimento.

Já no que tange ao regulador de crescimento AIB, novamente não se observaram efeitos das diferentes concentrações, tanto com relação à característica de altura das mudas aos 50 dias quanto ao diâmetro de colo, concordando com os resultados obtidos por Wendling (1999) e Titon (2001), quando trabalharam com clones de Eucalyptus.

\subsection{Matéria seca da parte aérea}

De forma geral, os subcultivos de miniestaquia seriada resultaram em maior matéria seca da parte aérea das mudas (Figura 6) somente no clone CC10, em que os subcultivos de números 5 e 7 resultaram em um aumento de $35,5 \%$ em relação aos de números 1 e 3 . Já no clone CC12 houve diminuição de $9,1 \%$ no peso de matéria seca da parte aérea dos subcultivos 1 e
3, em relação aos de números 5 e 7 . Esses resultados estão de acordo com os encontrados nas demais características, em que o clone CC10, de menor grau de juvenilidade, apresenta sempre certa resposta positiva à miniestaquia seriada.

Segundo Greenwood e Hutchison (1993), propágulos juvenis não somente produzem maior crescimento do caule, mas também maior quantidade de folhas e biomassa. O estádio juvenil possibilita o maior crescimento vegetativo da planta e a produção de grande área foliar, como também a produção de fotoassimilados (BOLIANI, 1986). Baseado nessas considerações e em função da resposta positiva ao rejuvenescimento somente pelo clone $\mathrm{CC} 10$ e negativa pelo clone CC12, pode-se concluir que o segundo apresentava um grau de juvenilidade bom para a característica de vigor aéreo, não respondendo à miniestaquia seriada, ao passo que o primeiro, com grau de juvenilidade menor, respondeu aos subcultivos.

Quanto ao AIB, de forma geral não se verificou influência positiva sobre a produção de matéria seca da parte aérea. Entretanto, nos clones CC10 e CC15, um efeito inibitório dessa característica pôde ser observado a partir da dosagem de $1.500 \mathrm{mg} \mathrm{L}^{-1} \mathrm{e}$, no clone CC12, a partir de $500 \mathrm{mg} \mathrm{L}^{-1}$.

\subsection{Matéria seca do sistema radicular}

Considerando-se a média de todas as concentrações de AIB aplicadas, o subcultivo 7 resultou em maior matéria seca da parte radicular das mudas (Figura 7) nos clones CC10, CC15 e CC14, em que se verificaram aumentos médios de 37, 49,1 e 30,3\%, respectivamente, em relação às médias dos subcultivos de números 1 , 3 e 5 . Já no clone CC12 praticamente não se observaram diferenças entre os subcultivos. Esses resultados estão de acordo com os de Titon (2001), cujos propágulos rejuvenescidos in vitro resultaram, de maneira geral, em maior peso de matéria seca do sistema radicular.

As auxinas exercem papel importante na diferenciação de meristemas para que a formação de raízes adventícias possa ocorrer (HARTMANN et al., 1997), além de outros fatores ambientais que também contribuem para essa ação, permitindo a suposição de que, quando os fatores ambientais aliados aos reguladores de crescimento internos responsáveis pela formação de raízes falharem em induzir a diferenciação ou o fizerem em taxas restritas, os reguladores exógenos atuam complementando a diferenciação.

R. Árvore, Viçosa-MG, v.29, n.6, p.921-930, 2005 


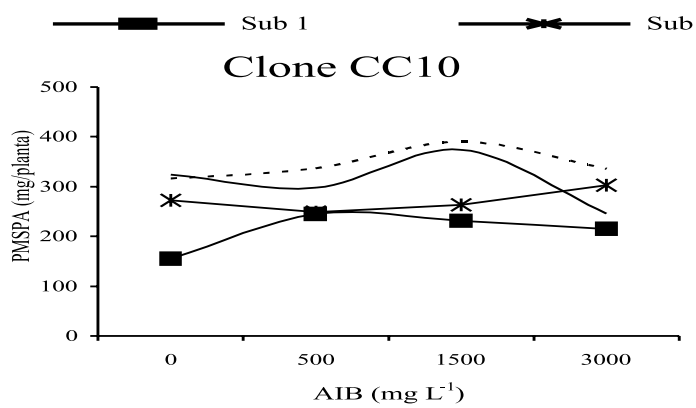

Clone $\mathrm{CC} 14$

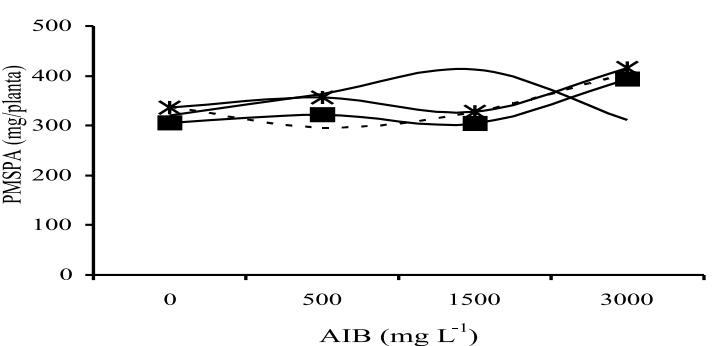

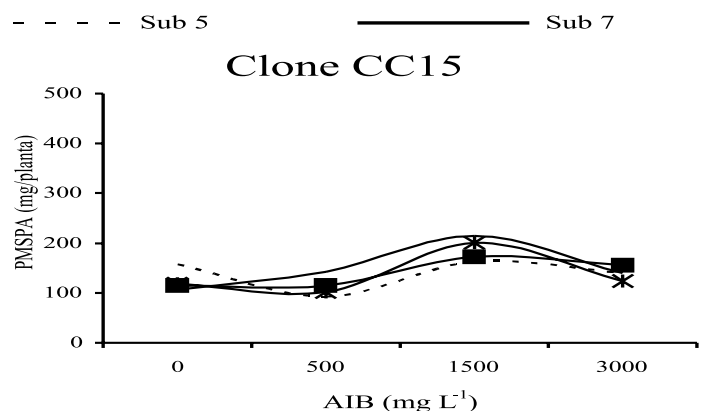

Clone CC12

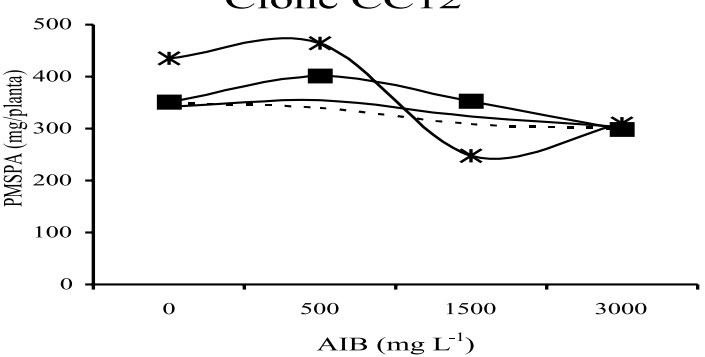

Figura 6 - Médias da matéria seca da parte aérea das mudas aos 50 dias (PMSPA), em resposta à aplicação de AIB (0, 500, 1.500 e $3.000 \mathrm{mg} \mathrm{L}^{-1}$ ), nos quatro subcultivos (Sub 1, Sub 3, Sub 5 e Sub 7) de miniestaquia seriada de clones de Eucalyptus grandis.

Figure 6 - Dry matter of the aerial part of rooted seedlings at 50 days of age (PMSPA), of Eucalyptus clones, in response to different dosages of the growth regulator AIB and four serial minicutting subcultures.
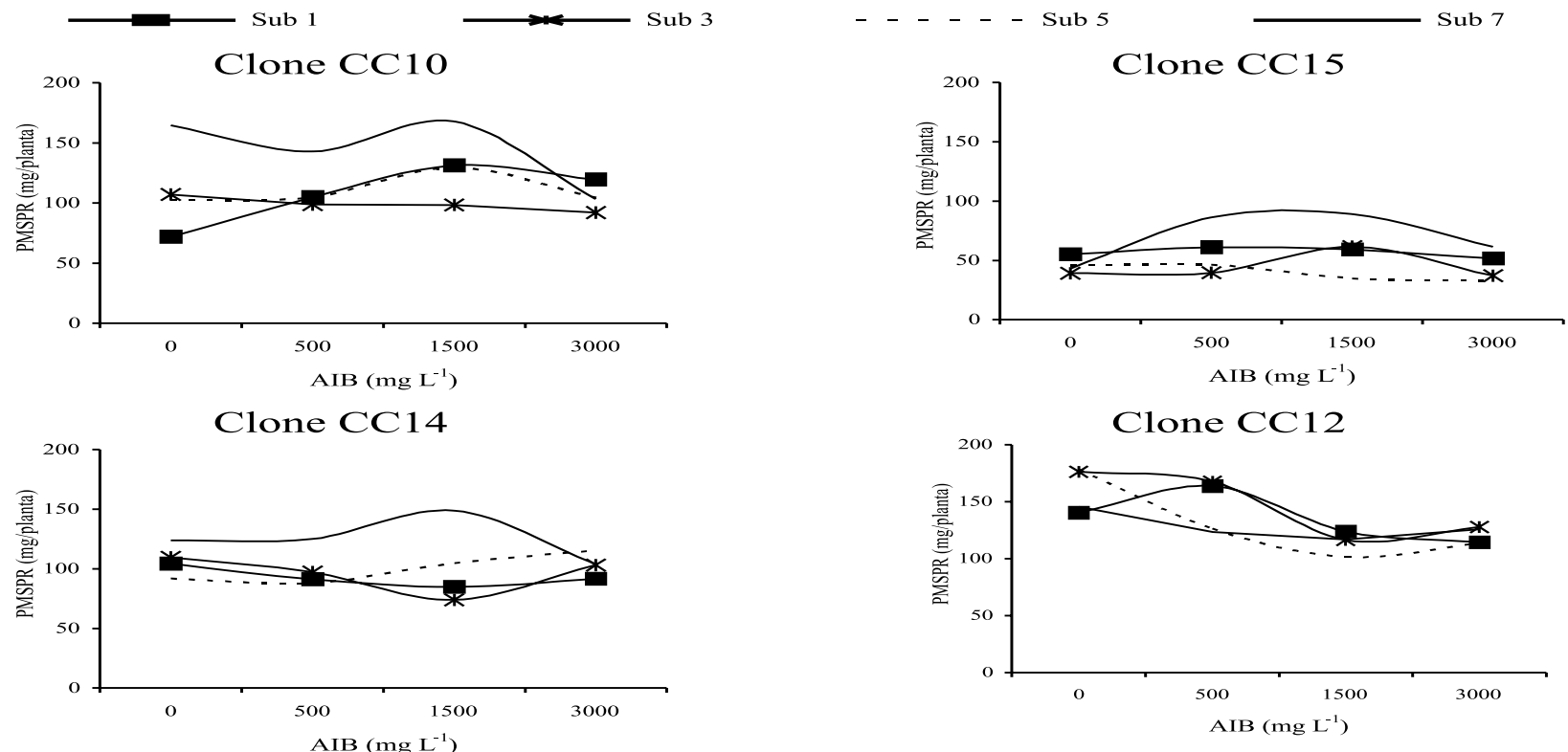

Figura 7 - Médias de matéria seca da parte radicular das mudas aos 50 dias (PMSPR), em resposta à aplicação de AIB $\left(0,500,1.500\right.$ e $\left.3.000 \mathrm{mg} \mathrm{L}^{-1}\right)$, nos quatro subcultivos (Sub 1, Sub 3, Sub 5 e Sub 7) de miniestaquia seriada de clones de Eucalyptus grandis.

Figure 7 - Dry matter of the radicular part of rooted seedlings at 50 days of age (PMSPR), of Eucalyptus clones, in response to different dosages of the growth regulator AIB and four serial minicutting subcultures.

R. Árvore, Viçosa-MG, v.29, n.6, p.921-930, 2005 
Baseado nisso, pode-se inferir que, no presente estudo, tanto os reguladores de crescimento internos quanto os fatores ambientais se encontravam em níveis e condições adequados, o que pode ser visualizado pelos bons índices gerais de enraizamento, de sobrevivência e vigor radicular obtidos, além do nãoefeito geral da aplicação do regulador de crescimento AIB sobre as características avaliadas. Além disso, segundo Van Staden e Harty (1987) e Skoog e Tsui (1951), citados por Cuquel (1992), altas relações internas de auxina/citocinina, características de plantas mais juvenis, promovem a formação de primórdios radiculares; e relações intermediárias promovem a formação de calo e, em relações baixas, não existem nem formação de calo nem enraizamento, apenas formação de gemas foliares.

Tudo isso ajuda a atestar a hipótese de um bom grau de juvenilidade dos clones empregados neste estudo, o que está de acordo com Xavier e Comério (1996), em cujo estudo propágulos rejuvenescidos pela micropropagação seriada não apresentaram resposta ao AIB aplicado, na técnica de microestaquia, resultando até em efeito inibitório. A adoção da técnica de miniestaquia em detrimento da de estaquia levou à redução (TITON, 2001; WENDLING et al., 2000) e, em alguns casos, até a eliminação total do uso de reguladores de crescimento para o enraizamento de Eucalyptus, constituindo, portanto, outro fator importante na avaliação dos efeitos do AIB no presente estudo.

Vale salientar que, em todas as características avaliadas, os coeficientes de determinação $\left(R^{2}\right)$ nas análises de regressão apresentaram valores baixos, não denotando confiabilidade das equações de regressão para explicar as respostas das características avaliadas em razão das aplicações de AIB, o que corrobora os resultados obtidos por Wendling et al. (2000) e Xavier et al. (2003), em estudos dentro dessa mesma linha de conhecimento.

\section{CONCLUSÕES}

De acordo com os resultados e as condições em que foram realizadas as pesquisas, conclui-se que:

- A miniestaquia seriada foi mais eficiente no rejuvenescimento de clones de Eucalyptus grandis com menor grau de juvenilidade, em relação às características de enraizamento, sobrevivência e do vigor da parte aérea e sistema radicular.
- Os clones estudados não responderam às aplicações de AIB quanto às características avaliadas, sendo em algumas características e clones observados certos níveis de toxidez nas concentrações acima de $500 \mathrm{mg} \mathrm{L}^{-1}$.

- Os diferentes subcultivos de miniestaquia seriada não proporcionaram resposta diferenciada à aplicação de AIB.

- O grau de rejuvenescimento obtido pela miniestaquia seriada foi variável em razão das características e dos clones avaliados.

\section{AGRADECIMENTOS}

À Celulose Nipo-Brasileira S.A. (CENIBRA), pela disponibilização do material experimental e pelo apoio orçamentário e estrutural na condução das pesquisas.

À Fundação de Amparo à Pesquisa do Estado de Minas Gerais (FAPEMIG) e à Federação das Indústrias de Minas Gerais (FIEMG), pela bolsa de estudos.

À Empresa Brasileira de Pesquisa Agropecuária (EMBRAPA), pelo apoio pessoal.

\section{REFERÊNCIAS BIBLIOGRÁFICAS}

ALVARENGA, L. R.; CARVALHO, V. D. Uso de substâncias promotoras de enraizamento de estacas frutíferas. Informe Agropecuário, v.9, n. 101, p. 47-55, 1983.

ASSIS, T. F.; ROSA, O. P.; GONÇALVES, S. I. Propagação por microestaquia. In: CONGRESSO FLORESTAL ESTADUAL, 7., 1992, Nova Prata. Anais... Santa Maria: UFSM, 1992. p. 824-836.

BOLIANI., A. C. Efeitos do estiolamento basal, da juvenilidade e do uso de um regulador vegetal no enraizamento de estacas de raízes e de ramos herbáceos de algumas espécies frutíferas. 1986, 129 f. Dissertação (Mestrado em Agronomia) - Escola Superior de Agricultura Luiz de Queiroz, Piracicaba, 1986.

CARneiro, J. G. A. Produção e controle de qualidade de mudas florestais. Curitiba: UFPR/FUPEF, 1995. 451 p.

R. Árvore, Viçosa-MG, v.29, n.6, p.921-930, 2005 
CHUNG, D. Y.; LEE, K. J. Effects of clones, ortet age, crown position, and rooting substance upon the rooting of cuttings of Japanese larch (Larix leptolepis S. et Z. Gordon). Forestry

Genetics Research Institute, v. 83, n. 2, p. 205-210, 1994. CD-ROM.

CUQUEL, F. L. Enraizamento de estacas de crisântemo Dendrathema morifolium tratadas com ácido indolbutírico. 1992. 66 f. Dissertação (Mestrado em Fitotecnia) Escola Superior de Agricultura Luiz de Queiroz, Piracicaba, 1992.

ELDRIDGE, K. et al. Eucalypt domestication and breeding. Oxford: Clarendon Press, 1994. p. 228-246.

FRANCLET, A. et al. Rejuvenation. In: BONGA, J. M.; DURZAN, D. J. Cell and tissue culture in forestry. Dordrecht: Kluwer Academic Publishers, 1987. v.1. p.232-248.

GREENWOOD, M. S.; HUTCHISON, K. W. Maturation as an developmental process. In: AHUJA, M. R.; LIBBY, W. J. Clonal forestry: genetics and biotecnology. Budapest: SpringerVerlag, 1993. p. 14 - 33.

HACKETT, W. P.; MURRAY, J. R. Maturation and rejuvenation in woody species. In: AHUJA, M. R. Micropropagation of $\operatorname{woody}$ plants. Dordrecht: Kluwer Academic Publishers, 1993.p. 93 - 105.

HARTMANN, H. T. et al. Plant propagation; principles and practices. 6 ed. New Jersey: Prentice-Hall, 1997. 770 p.

HUANG, L. C. et al. Rejuvenation of trees and other perennials for restoration of plant regeneration competence. In: TORRES, A. C.; CALDAS, L. S. Técnicas e aplicações da cultura de tecidos em plantas. Brasília: ABCTP/EMBRAPA-CNPH, 1990, p. 252 - 264.

IKEMORI, Y. K. Resultados preliminares sobre enraizamento de estacas de Eucalyptus spp. Aracruz: 1975. p. 12

(Informativo Técnico Aracruz, 1).

KAMLESH, K. et al. Effect of auxins and carbendazim on rooting of juvenile and mature stem cuttings of Grewia optiva. Indian Journal of Forestry, v. 18, n. 1, p. 61-65, 1995. CD-ROM.
LAINE, E.; DAVID, A. Regeneration of plants from leaf explants of micropropagated clonal Eucalyptus grandis. Plant Cell Reports, v.13, n. 8, p. 473-476, 1994. CD-ROM.

LOPES, L. C.; BARBoSA, J. G. Propagação de plantas ornamentais. Viçosa, MG: UFV, 1988. 30 p. (Boletim, 267).

TITON, M. Propagação clonal de Eucalyptus grandis por miniestaquia e microestaquia, 2001. 65 f. Dissertação (Mestrado em Ciência Florestal) - Universidade Federal de Viçosa, Viçosa, 2001.

Van STADEN, J.; HARTY, A. R. Cytokinins and adventitious root formation. In: DAVIES, T. D.; HAISSIG, B. E.; SANKHLA, N. Adventitious root formation in cuttings. Portland: Dioscorides Press, 1987. p. 185 - 201. (Advances in Plant Sciences Series, 2).

WEndling, I. Propagação clonal de híbridos de Eucalyptus spp. por miniestaquia. 1999. 70 f. Dissertação (Mestrado em Ciência Florestal) - Universidade Federal de Viçosa, Viçosa, 1999.

WENDLING, I. Rejuvenescimento de clones de Eucalyptus grandis pela técnica de miniestaquia e micropropagação seriada. 2002. 98 f. Tese (Doutorado em Ciência Florestal) - Universidade Federal de Viçosa, Viçosa, 2002.

WENDLING, I. et al. Efeito do regulador de crescimento AIB na propagação de clones de Eucalyptus spp. por miniestaquia. Revista Árvore, v. 24, n. 2, p. 187-192, 2000.

WILSON, P. J. The concept of a limiting rooting morphogen in woody stem cuttings. Journal of Horticultural Science, v. 9, n. 4, p. 391-400, 1994.

XAVIER, A.; COMÉRIO, J. Microestaquia: uma maximização da micropropagação de Eucalyptus. Revista Árvore, v.20, n.1, p.9-16, 1996.

XAVIER, A. et al. Desempenho do enraizamento de microestacas e miniestacas de clones de híbrido de Eucalyptus grandis. Revista Árvore, v. 25, n. 4, p. 403-411, 2001.

XAVIER, A. et al. Propagação vegetativa de cedro-rosa por miniestaquia. Revista Árvore, v. 27 , n. 2, p. 139-143, 2003. 